\title{
THE EFFECT OF FIN'S HEIGHT AND CIRCULAR PERFORATED ON THE NATURAL CONVECTION OF THE VERTICAL RECTANGULAR FINS
}

\author{
Ali A. F. Al-Hamadani, \\ Department of Mechanical Engineering, College of Engineering, Wasit University, Wasit, Iraq. \\ E-mail:aalhamadani@uowasit.edu.iq \\ Khaleel Saleem Jebur Ogaili, \\ Department of Mechanical Engineering, College of Engineering, Wasit University, Wasit, Iraq. \\ E-mail: Khaleel.Ogaili@usq.edu.au
}

\begin{abstract}
Ahmed A. Y. Al-Waaly,
Department of Mechanical Engineering, College of Engineering, Wasit University, Wasit, Iraq.

E-mail: aalwaaly@uowasit.edu.iq
\end{abstract}

Received on 24 August 2017 Accepted on 13 December 2017 Published on 20 February 2018 DOI: $10.30772 / q j e s . v 10 i 4.505$

\begin{abstract}
The safe operation of any device is necessary, but it requires a suitable condition such as dissipated the heat generated. A heat sink with vertical rectangular fins was improved using a circular perforated with diameter of $6 \mathrm{~mm}$ for different fins height 6 $\mathrm{cm}, 8 \mathrm{~cm}$ and $10 \mathrm{~cm}$. An experimental study was conducted to investigate the effect of circular perforated on the natural convection heat transfer of a vertical rectangular fin. Different numbers of circular perforated 2, 3 and 5 were studied. The results showed that the heat transfer for the height $6 \mathrm{~cm}$ is higher as compared with $8 \mathrm{~cm}$ and $10 \mathrm{~cm}$. Moreover, the coefficient of heat transfer increases with the increased of the number of the circular perforation. For the fin height $6 \mathrm{~cm}$ with five circular perforated, the heat transfer coefficient of the natural convection is $30 \mathrm{~W} / \mathrm{m}^{2}{ }^{\circ} \mathrm{C}$.
\end{abstract}

Keywords: Fins, Natural, Circular Perforated, Heat transfer, Experimental.

\section{INTRODUCTION}

The enhancement of heat transfer by natural convection is an essential matter of thermal applications. The reduction of the extreme heat rate from electronic devices is necessary to ensure steady and continuous safe operation. The heat transfer can be improved by increasing the heat transfer area between the heat transfer surface and the outside environment. The extended surfaces (fins) are used to increase heat transfer in many applications. The rectangular fins are frequently used because of their easy construction, inexpensive cost and active cooling capability. Burak Y. [1] studied different sets of rectangular fins with 


\section{AL-QADISIYAH JOURNAL FOR ENGINEERING SCIENCES}

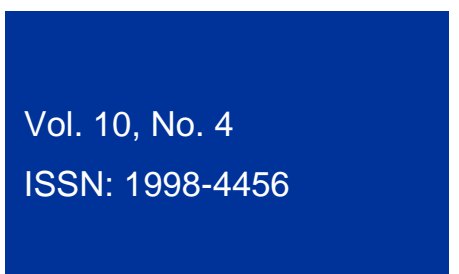

natural convection. The fin length and fin spacing was varied with constant thickness of $3 \mathrm{~mm}$. The input heat supplied was varied from $25 \mathrm{~W}$ to $125 \mathrm{~W}$. Burak $\mathrm{Y}$. concluded that the best fin spacing is between 0.88 $\mathrm{cm}$ and $1.47 \mathrm{~cm}$.

Mahdi F. et al. [2] simulated the free convection on vertical surfaces using computational fluid dynamic software. They concluded that heat transfer rate increases for fin spacing 5.84 and $6.42 \mathrm{~mm}$, after that the heat transfer rate starts to decrease. Mahdi F. et al. confirmed that the coefficient of natural convection varies with the fin's height, length, fin spacing, and the temperature difference between fin's and the ambient temperature. Goshayeshi, et al. (2009) [3] investigated numerically the effect of horizontal and vertical surface of the fin on the fin's performance. The results demonstrate that the vertical plate with vertical fins gives the greatest performance for normal cooling.

Al-Widyan, et al. [4] investigated the effect of circular perforations attached to the surface on the performance of a rectangular fin. Their numerical analysis shows that the heat transfer from the perforated fin increased with Grashof number and reduction of the spacing between the holes. Golnoosh Mostafavi et al. [5] studied steady-state of rectangular interrupted fin arrays. They concluded that adding of interruptions to a single vertical plate will improve heat transfer characteristics. They developed a new relationship to calculate the Nusselt. Ali, et al. [6] presented numerical and experimental analyses for a forced convection through staggered punched pin fins in a rectangular channel. They concluded that Nusselt number is increased with horizontal/vertical (HV) perforations than those for solid pins. Wadhah et al. [7] examined the behavior of heat sinks with different number of circular perforations in a rectangular fin plate. They found the coefficient of heat transfer increased with number of holes. Numerical results of Shaeri, et al. [8] showed that the rectangular perforated fins gave higher heat transfer than the solid fins.

In the present study the combined effect of fin length with a number of circular perforated for optimized the performance of the fin has not been studied. Therefore, an experimental work has been achieved to know the combined effect of fin length with many circular perforated. To do this purpose the six fins configuration was used.

\section{MATERIALS METHODS}

The study analyzed of free convection from rectangular extended surface (fins) with circular perforated has been investigated. This type of fins used to enhance the heat transfer and the area of heat transfer. The number and dimension of perforations were significant paremeter on heat dissipation [7]. The behavior of thermal performance of fins can be analyzed. The length and width of heat sink were $300 \mathrm{~mm}$ and $110 \mathrm{~mm}$ respectively. The heat supplied (Qgen) through base plate and fins by using heater. The heat transferred across the fin by conduction Qcond. The other mode of heat transfer such as convection and radiation also occur between the fins and surrounding [9].

$$
Q_{\text {gen. }}=Q_{\text {conv. }}+Q_{\text {rad. }}
$$

The heat generating is calculated as follows: -

$$
Q_{g e n .}=V \times I
$$


The heat transferred by radiation is calculated as follows: -

$$
Q_{\text {rad. }}=\sigma \times \varepsilon \times S_{\text {sur }} \times A_{t}\left(T_{\text {avo }}^{4}-T_{\text {air }}^{4}\right)
$$

Where:

$\varepsilon$ : emissivity surface factor equal to (0.04) [4]

Ssur: shape factor and equal $=1[4]$

Therefore, the heat transferred is calculated by convection as follows:

$$
Q_{\text {conv. }}=Q_{\text {gen. }}-Q_{\text {rad. }}
$$

Equation 5 determine the heat transfer coefficient in free convection:

$$
h=\frac{Q_{\text {conve }}}{A_{\pi} \Delta T}
$$

The area of base plate is :

$$
A_{b}=l * W(6)
$$

Area of circular perforated :

$$
A_{c p}=n_{c p} * \frac{\pi}{4} * d^{2}(7)
$$

Exposed fin area :

$$
A_{f}=\left((l * H * 2)-A_{c p}\right)+(t * H * 2)+(l * t)
$$

Totally exposed area :

$$
A_{t}=n * A_{f}+l * s *(n-1)
$$


Then, the total surface area with six fins is $0.2412 \mathrm{~m}^{2}$. The difference temperature in equation (5) represents the average temperature of the base fin and the air temperature. The temperature of the base fin is calculated as follows:

$$
T_{\text {avi }}=\frac{\left(T_{1}+T_{2}+\cdots+T_{n}\right)}{n}
$$

The film temperature $\left(T_{f}\right)$ is computed by eq. 11 :

$$
T_{f}=\frac{T_{\text {av }}+T_{\text {air }}}{2}
$$

This temperature is taken to calculate the physical properties of the working fluid (air). According to the values of temperature and physical properties taken from the tables in reference [4], Any physical property at any temperature within the range used in this study can be obtained.

Nusselt number is determined by eq. 12: -

$$
N u=\frac{h L}{K_{f}}
$$

\section{EXPERIMENTAL SETUP AND METHODOLOGY}

Six fins were inserted into a rectangular aluminum base. The base plate dimensions are $L=300 \mathrm{~mm}$ and $W=110 \mathrm{~mm}$ with base thickness equal to $10 \mathrm{~mm}$. Different fins heights have been chosen $(60,80$ and $100 \mathrm{~mm}$ ) with thickness $\mathrm{t}=5 \mathrm{~mm}$ and different number of perforates $\mathrm{N}=2,3,5$. Fins spacing was $\mathrm{S}=12.5 \mathrm{~mm}$. Figure 1 shows rectangular fins with five circular perforated heat sink.

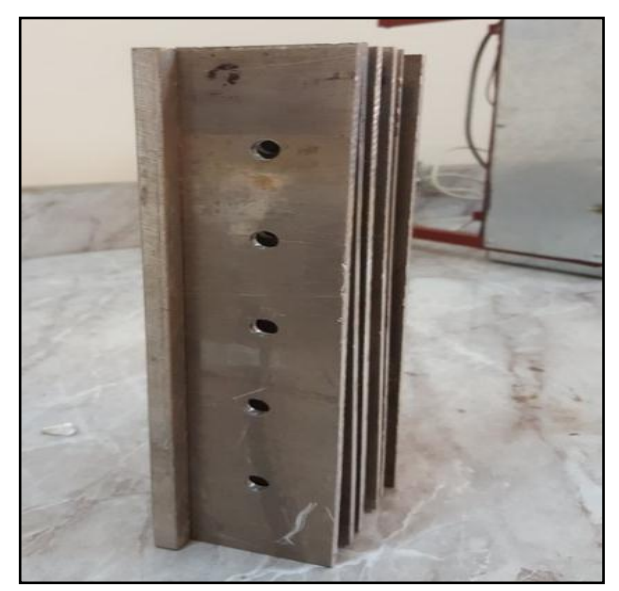

Figure 1: The photograph of the fins Geometry. 


\section{AL-QADISIYAH JOURNAL FOR ENGINEERING SCIENCES}

Vol. 10, No. 4

ISSN: $1998-4456$

The following procedure has been followed:

The fins have been inserted into grooves in the base plate to form fin arrays.

The fins array was placed on four electric heaters to mimic heat generation.

Six thermocouples were fixed at different positions on the base plate.

A voltage regulator was used to supply five different voltages (50, 75, 100, 125 and 150 V) to generate various heat fluxes.

Temperature measurements were recorded using digital thermometer. Ambient temperature was measured. The temperature measurements were recorded until a steady state is achieved.

Average temperature of the thermocouples was calculated.

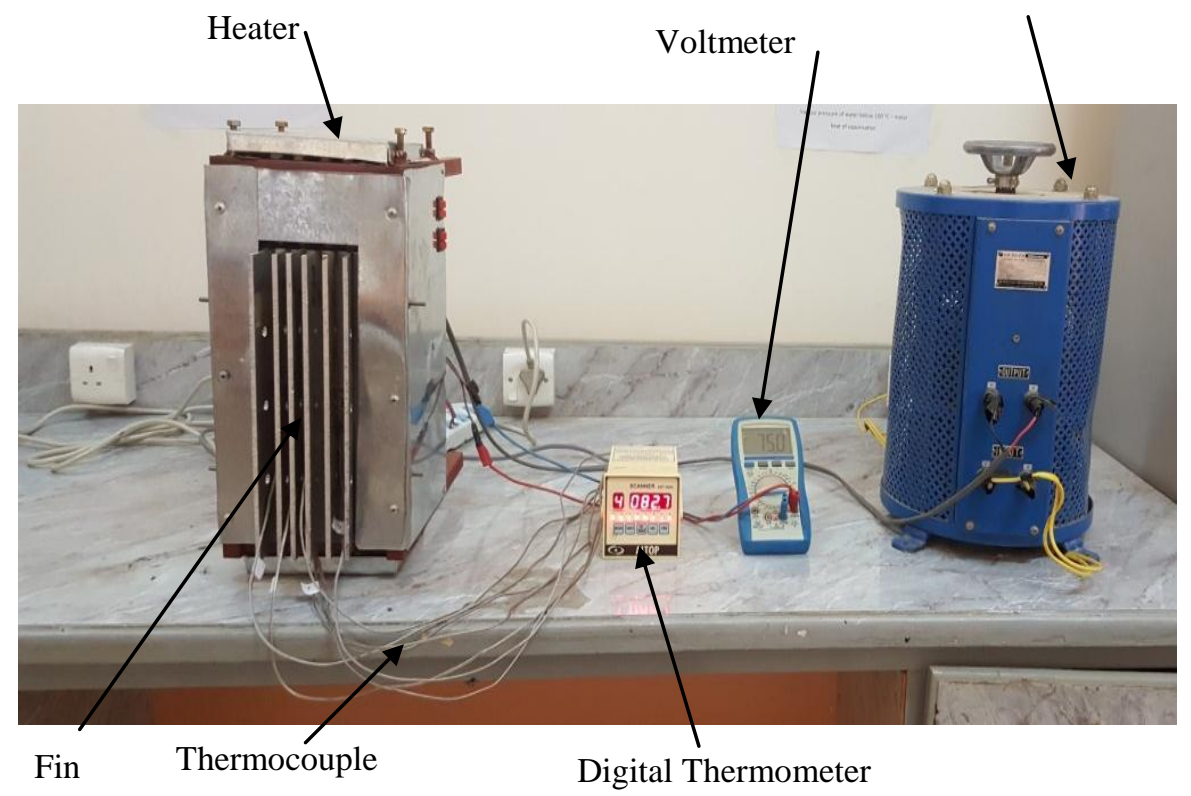

Figure 2: Photograph of the test rig with the measuring instruments.

\section{RESULTS AND DISCUSSION}

Different fin heights have been investigated with varying the size of the circular perforated. The erformance of fins was estimated by using $\mathrm{Nu}, \mathrm{h}$ and $\mathrm{Ra}$. The first experiment that used different fin of circular perforated (Fcp) with 2,3 and 5 number of fins and height length of fin 6,8 and $10 \mathrm{~cm}$.

Figure 3 shows the heat transfer coefficient (h) with temperature differences (Tav -Tair), Nu and Tav for fin of circular perforated (FCp) with 2,3 and 5 number of fins of 6,8 and $10 \mathrm{~cm}$ height of fin respectively. It showed the heat transfer coefficient and Nu were increased with fins of two circular perforated (Fcp2) with 6 $\mathrm{cm}$ fin's height. The is due to the small surface area of the fin(s), see Eq(5). 


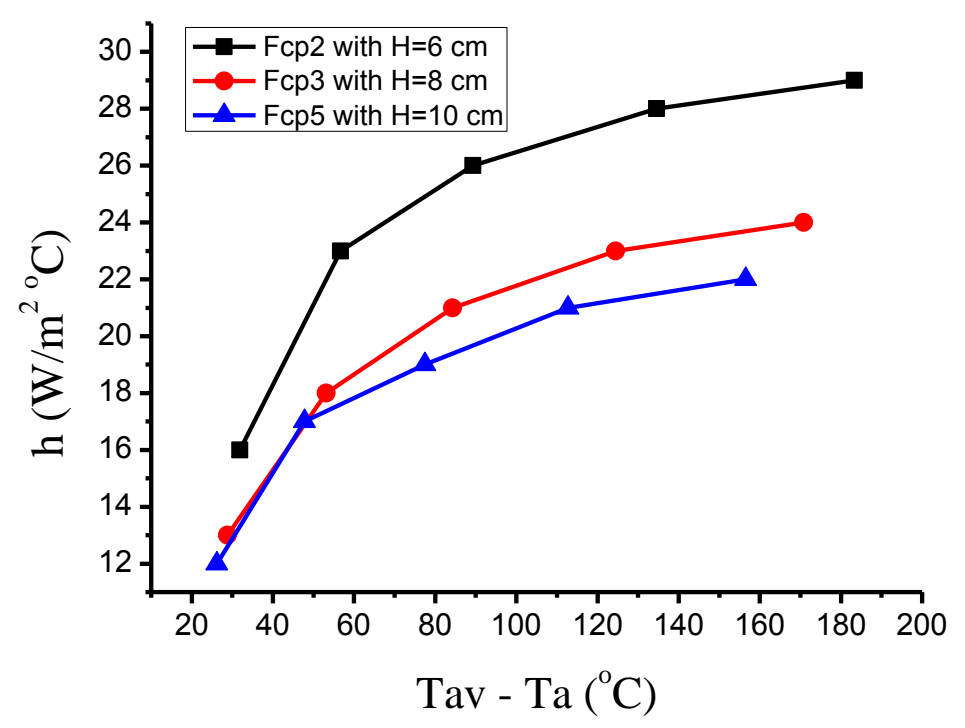

Figure 3: The heat transfer coefficient and temperature difference for different fin height and different number of circular perforated.

Figure 4 depicts the heat transfer coefficient (h) and the rate of heat transfer Qc with different height of fin. The enhancement in heat transfer of Fcp2 with $6 \mathrm{~cm}$ fin's height is higher than the others.

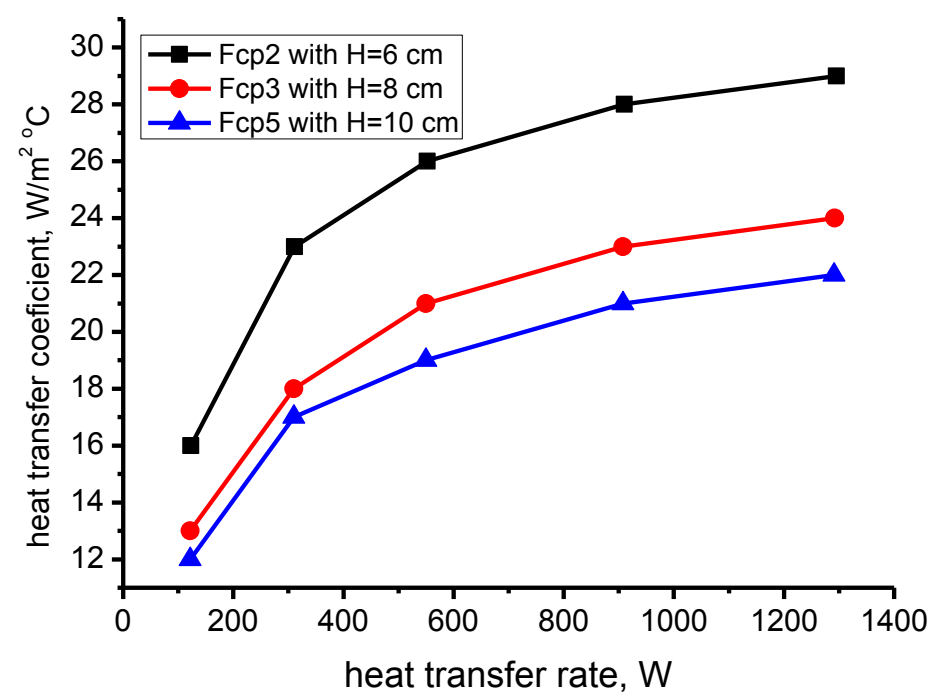

Figure 4: Heat transfer coefficient and the rate of heat transfer for different Fcp with different fin height. 


\section{AL-QADISIYAH JOURNAL FOR ENGINEERING SCIENCES}

Vol. 10, No. 4

ISSN: $1998-4456$

Figure 5 previal the Nu number and temperature differences for different Fcp. The fin of $6 \mathrm{~cm}$ height of fin give high Nu approximately 270 which is represented high value if we compared with 8 and $10 \mathrm{~cm}$. the enhancement due to less area with $6 \mathrm{~cm}$.

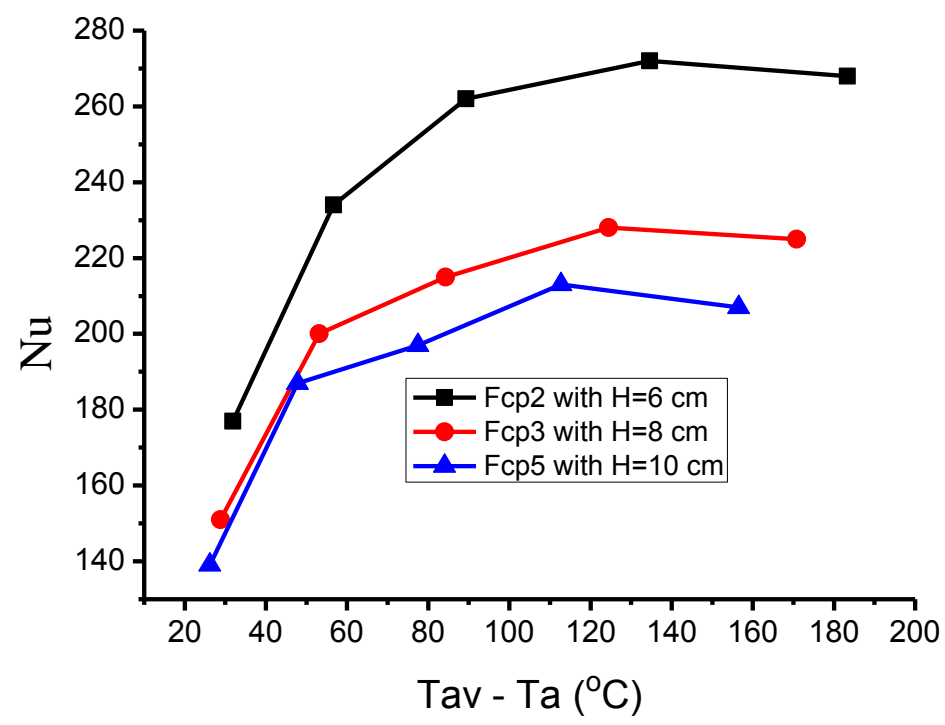

Figure 5: Variation of Nu with temperature different for different Fcp with different fin height.

The number of Fcp has been investigated with different fin height as shown Figures 6 and 7.

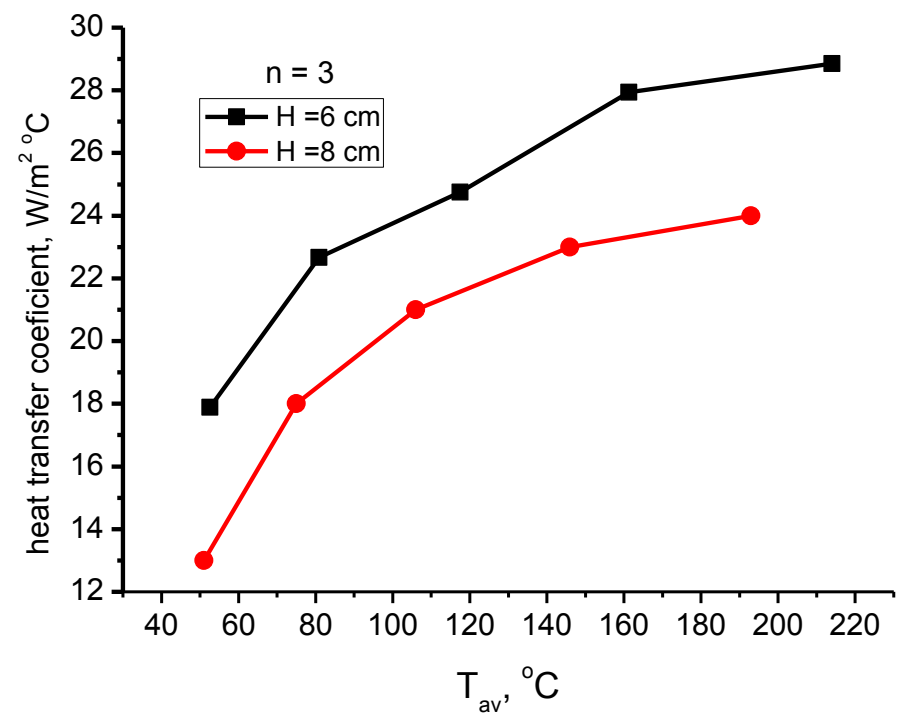

Figure 6: The heat transfer coefficient with the average temperature for height of fins 6 and $8 \mathrm{~cm}$ with with Fcp3.

It prevail that the Fcp5 give high heat transfer coefficient as well as the best fin height was $6 \mathrm{~cm}$. This results because when increased the no of circular perforated will cause enhancement of heat transfer. Furthermore the fins will become lighter from other and Fcp5 has economical benefit. 


\section{AL-QADISIYAH JOURNAL FOR ENGINEERING SCIENCES}

Vol. 10 , No. 4

ISSN: $1998-4456$

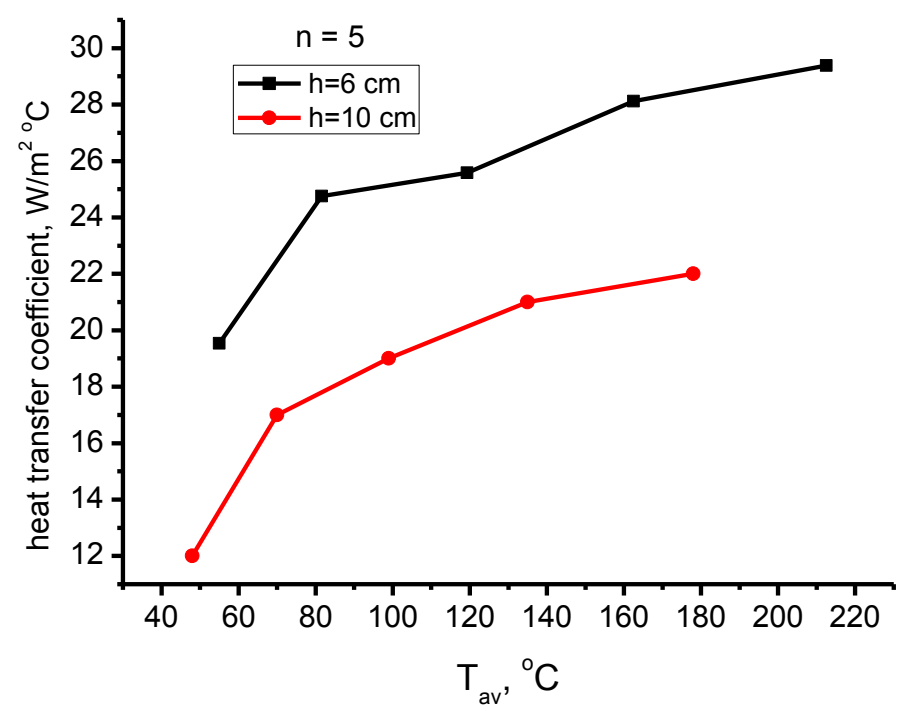

Figure 7: The heat transfer coefficient with the average temperature for height of fins 6 and $10 \mathrm{~cm}$ with Fcp5.

\section{CONCLUSIONS}

The study was carried out to examine the fin with circular perforations as heat sinks. The experimental work was conducted. The set of the perforations included 2,3 and 5 circular perforations (holes) for fin height 6,8 and $10 \mathrm{~cm}$ respectively. The effects of different fin height, number of circular perforated and heat flux on the performance of fin collections was showed. The heat transfer coefficient enhanced for Fcp2 with $\mathrm{H}=6 \mathrm{~cm}$ compared with $\mathrm{Fcp} 3$ with $\mathrm{H}=8 \mathrm{~cm}$ and $\mathrm{Fcp} 5$ with $\mathrm{H}=10 \mathrm{~cm}$. The heat transfer increase with height of fin the best one with $\mathrm{Fcp} 2$ with $\mathrm{H}=6 \mathrm{~cm}$. The Nu increased with $\mathrm{Ra}$ and the max $\mathrm{Nu}$ is 270 with $\mathrm{Fcp} 2$ with $\mathrm{H=} 6 \mathrm{~cm}$. For the fin height $6 \mathrm{~cm}$ with five circular perforated, the heat transfer coefficient of the natural convection was $30 \mathrm{~W} / \mathrm{m} 2$ oC.

\section{ACKNOWLEDGEMENTS}

The authors would like to acknowledge the Department of Mechanical Engineering, College of Engineering, Wasit University for their support to do the experimental work.

\section{REFERENCES}

1. Yazicioğlu, B., Performance of Rectangular fins on vertical base in free convection, M.Sc. Thesis Technical University of Middle East, 2005.

2. Fahiminia, M.; Naserian, M.M.; Goshayeshi, H.R.; Majidian, D., Investigation of Natural Convection Heat Transfer Coefficient on Extended Vertical Base Plats, Energy and Power Engineering, 3, 174-180, 2011.

3. GOSHAYESHI, H. R; AMPOFO, F. Heat Transfer by Natural Convection from a Vertical and Horizontal Surfaces Using Vertical Fins, Energy and Power Engineering, 85-89. DOI:10.4236/epe.(2009).1201, 2009.

4. Al-Widyan, M.I.; and Al-Shaarawi, A., Numerical Investigation of Heat Transfer Enhancement for a Perforated Fin in Natural Convection, International Journal of Engineering Research and Applications (IJERA), 2, Issue 1, 175-184, 2012. 


\section{AL-QADISIYAH JOURNAL FOR ENGINEERING SCIENCES}

Vol. 10, No. 4

ISSN: 1998-4456

5. Mostafavi, G.; Ahmadi, M., Effect of fin interruption on natural convection heat transfer from a rectangular interrupted single-wall, Proceedings of the ASME 2013 International Technical Conference and Exhibition on Packaging and Integration of Electronic and Photonic Microsystems InterPACK2013, Burlingame, CA, USA. p. 1-8, 2013.

6. Baqir, A.S.; Qasim, A.; Adnan, A., Experimental study for staggered perforated array of pins link fins in a rectangular air cross flow, The Iraqi Journal for Mechanical And Material Engineering, 14, No. 2, 261-275, 2014.

7. Al- Doori, W.H.A., Enhancement of Natural Convection Heat Transfer from Rectangular Fins by Circular Perforations, International Journal of Automotive and Mechanical Engineering (IJAME), 4, 428-436, 2011.

8. Shaeri, M.R.; Yaghoubi, M.; Jafarpur, K., Heat transfer analysis of lateral perforated fin heat sinks, Applied Energy, 86, 2019-2029, 2009.

9. Incropera, F.P.; DeWitt, D.P.; Bergman, T.L.; Lavine, A.S., Fundamentals of Heat and Mass Transfer, John Wiley \& Sons; 6th edition (March 10, 2006). 